\title{
Sutureless aortic valve replacement and direct Sapien 3 valve-in-valve implantation: a challenging case
}

\author{
Carlo Savini, Gregorio Gliozzi, Carlo Mariani, Daniela Votano, Alessandro Leone, Davide Pacini \\ Cardio-Thoracic and vascular Department, Division of Cardiac Surgery, S.Orsola Hospital, Bologna University, Bologna, Italy \\ Correspondence to: Carlo Savini, MD. c/o Unità Operativa di Cardiochirurgia, Università degli Studi di Bologna, Policlinico S.Orsola-Malpighi, Via \\ Massarenti, 9, 40138 Bologna, Italy. Email: carlo.savini@aosp.bo.it.
}

Submitted Dec 16, 2019. Accepted for publication Jan 28, 2020.

doi: $10.21037 /$ acs.2020.02.13

View this article at: http://dx.doi.org/10.21037/acs.2020.02.13

\section{Clinical vignette}

A 72-year-old female was referred to our center for heart failure due to concomitant mitro-aortic biological prosthesis malfunction (severe mitral stenosis with mean gradient $11 \mathrm{mmHg}$ and severe aortic stenosis AVA $0.55 \mathrm{~cm}^{2}$ ) and severe tricuspid regurgitation. The patient was very frail (body mass index of $19.11 \mathrm{~kg} / \mathrm{m}^{2}$, Logistic euroSCORE II $22.9 \%$; Society of Thoracic Surgeons score 12.9\%), with a history of permanent atrial fibrillation and post-capillary pulmonary hypertension (PAPs/d/m 76/29/46 mmHg) requiring supplemental oxygen. We performed sutureless aortic valve replacement (SU-AVR) with Perceval S (LivaNova, London, United Kingdom), open mitral valve-in-valve procedure with Edwards Sapien 3 (Edwards Lifescience, Irvine, California, USA) and tricuspid valve annuloplasty.

\section{Surgical technique}

\section{Preparation \& exposition}

The patient was intubated with a standard endotracheal tube and positioned supine. Through a full median sternotomy, cannulation of the ascending aorta and superior vena cava was performed. A percutaneous femoral vein cannulation was used for inferior vena cava drainage.

Myocardial protection was achieved with antegrade single dose of HTK solution crystalloid cardioplegia (Custodiol $^{\circledR}$ ).

\section{Operation}

Mitral valve prosthesis was exposed through a transseptal access. In order to avoid partial obstruction of the left ventricular outflow tract (LVOT), the bioprosthesis cusp corresponding to the native anterior annulus of the mitral valve was removed. A $29 \mathrm{~mm}$ Edwards Sapien 3 transcatheter heart valve prosthesis was prepared with a simplified full crimping process. The prosthesis was then inserted into the old degenerate bioprosthesis ring and expanded under direct vision according to the valvein-valve technique. The correct movement of the valve leaflets and the appropriate positioning was checked intraoperatively with a water test. The interatrial septum was then closed with direct suture. We then proceeded to address the aortic bioprosthesis via a transverse aortotomy. The old degenerated prosthesis was removed. The transcatheter mitral valve (TMV) was clearly visible through the aortic valve in a good position with no obstruction of the LVOT. After aortic annulus sizing, a size S Livanova Perceval sutureless prosthesis was selected and prepared for implantation. Three monofilament 4-0 guiding suture were placed in the virtual nadir of the aortic sinus. The collapsed prosthesis was then crimped and implanted with its delivery system through the 'nadir' guide-wires. The Perceval S release system was then carefully extracted to avoid any collision with the TMV stent emerging in the LVOT. After good positioning of the aortic valve, we proceeded with the balloon dilatation. The absence of interference between the TMV and the Perceval prosthesis was verified and the aortotomy was closed with a continuous double layer suture. Finally, a tricuspid valve repair was performed with a size 28 Contour 3D (Medtronic, Minneapolis, Minnesota, USA) ring with a good intra-operative result. 


\section{Completion}

Postoperative echocardiogram showed good performance of the Perceval valve in the aortic position as well as the Sapien valve in the mitral position. The relationship between the new prosthesis compared with preoperative ones could be appreciated on the postoperative computed tomography angiography scan.

Postoperative course was uneventful and the patient was discharged twelve days after the surgery in good clinical condition.

At 18-month follow up, the patient was in NYHA class II with no signs or symptoms of heart failure, a reduction in pulmonary arterial pressures and no requirement for supplemental oxygen.

\section{Comments}

\section{Clinical results \& advantages}

Surgical planning in high risk patients is demanding, especially in patients not suitable for transcatheter therapy. A tailored treatment is then mandatory to reduce surgical trauma and improve the outcomes. The choice of surgical access, cannulation site and valvular prosthesis is crucial to reduce operative time and surgical burden.

Though central cannulation is preferable, it is not always suitable in cases of easy re-entry. The use of both central and peripheral cannulation, as proposed in this case, makes for easier and faster anatomical dissection, improves cardiopulmonary bypass performance and makes the surgical field clearer.

Sutureless rapid deployment and transcatheter valve prosthesis have demonstrated a significant reduction in cross-clamp and cardiopulmonary bypass times and surgical trauma, both in minimally invasive or conventional approach, becoming a safe and effective option for high risk patients (1). Sutureless aortic prostheses have been suggested in cases of small aortic root and minimally invasive AVR, reducing cardiopulmonary bypass and clamp time with excellent hemodynamic performance and low rate of patient-prosthesis mismatch rather than conventional aortic valve prosthesis (2). Recently, sutureless prostheses have been also approved for their use in combined mitroaortic procedure and successful multivalvular implants have been reported (3).

Transcatheter prosthesis nowadays is the gold standard for treatment of aortic valve stenosis in high- and mediumsurgical risk patients; furthermore, this technology can be used in the 'open' method.

Open mitral valve replacement with transcatheter prosthesis is an acknowledged bailout resource for extensive calcification of native annulus or in cases of reintervention for structural valve deterioration (4). Furthermore, it is used more and more with off-label indications in extremely complex situations.

\section{Caveats}

In mitro-aortic surgery the mitral valve is usually replaced first, preserving mitral geometry and favoring a correct sizing. Moreover, a challenging drawback of mitral prosthesis deployment is the LVOT partial obstruction, which depends on anatomical features such as aorto-mitral angle and anterior leaflet dislocation (5). In order to avoid this complication, the prosthetic "anterior leaflet" has to be removed.

The nitinol cage of Sapien prosthesis was clearly visible from the aortic root, with patent LVOT, but it may potentially interfere with the correct introduction of the delivery system of Perceval prosthetic valve.

Whilst the conventional order of transcatheter mitral valve replacement (TMVR) followed by AVR was effective in this case, we felt that changing this order (AVR first, TMVR second) would have been a good option.

\section{Acknowledgments}

This manuscript was written and produced upon invitation by the Guest Editors and Editor in Chief to contribute to the Annals of Cardiothoracic Surgery (ACS) special issue "Sutureless \& Rapid Deployment Aortic Valve Replacement".

\section{Footnote}

Conflicts of Interest: The authors have no conflicts of interest to declare.

Open Access Statement: This is an Open Access article distributed in accordance with the Creative Commons Attribution-NonCommercial-NoDerivs 4.0 International License (CC BY-NC-ND 4.0), which permits the noncommercial replication and distribution of the article with the strict proviso that no changes or edits are made and the original work is properly cited (including links to both the formal publication through the relevant DOI and the license). 
See: https://creativecommons.org/licenses/by-nc-nd/4.0/.

\section{References}

1. Santarpino G, Berretta P, Fischlein T, et al. Operative outcome of patients at low, intermediate, high and 'very high' surgical risk undergoing isolated aortic valve replacement with sutureless and rapid deployment prostheses: results of the SURD-IR registry. Eur J Cardiothorac Surg 2019;56:38-43.

2. Borger MA, Moustafine V, Conradi L, et al. A randomized multicenter trial of minimally invasive rapid deployment versus conventional full sternotomy aortic valve

Cite this article as: Savini C, Gliozzi G, Mariani C, Votano D, Leone A, Pacini D. Sutureless aortic valve replacement and direct Sapien 3 valve-in-valve implantation: a challenging case. Ann Cardiothorac Surg 2020;9(4):341-343. doi: 10.21037/ acs.2020.02.13 replacement. Ann Thorac Surg 2015;99:17-25.

3. Baran C, Durdu MS, Gumus F, et al. Sutureless aortic valve replacement with concomitant valvular surgery. J Thorac Cardiovasc Surg 2018;155:2414-22.

4. Praz F, Khalique OK, Lee R, et al. Transatrial implantation of a transcatheter heart valve for severe mitral annular calcification. J Thorac Cardiovasc Surg 2018;156:132-42.

5. Wyler von Ballmoos MC, Kalra A, Reardon MJ. Complexities of transcatheter mitral valve replacement (TMVR) and why it is not transcatheter aortic valve replacement (TAVR). Ann Cardiothorac Surg 2018;7:724-30. 